\title{
НОВІ ДАНІ ДО ХРОНОЛОГІЇ СТРАТИФІКОВАНОГО ПОСЕЛЕННЯ САБАТИНІВКА І
}

\author{
Дмитро Кіосак', Олена Секерська ${ }^{2}$ \\ 1 Одеський національний університет імені I.I. Мечникова (Одеса, Україна) \\ e-mail: dkiosak@ukr.net; ORCID: https://orcid.org/0000-0002-3349-4989 \\ 2 Південноукраїнський національний педагогічний університет \\ імені К.Д. Ушинського (Одеса, Україна) \\ e-mail: e.sekerskaja@gmail.com; ORCID: https://orcid.org/0000-0003-4540-3308
}

\begin{abstract}
У роботі публікуються чотири нові радіовуглецеві визначення, які спрямовані на вирішення актуальної проблеми абсолютної хронології двох шарів Сабатинівського поселення - нижнього (Трипілля В1) та верхнього (доба пізньої бронзи). Одержані дані свідчать на користь існування нижнього шару у межах XLIV-XLII Cm. до н.е., а верхнього - XVIXV cm. до н.е.
\end{abstract}

Ключові слова: радіовуглецевий аналіз, Трипілля B1, сабатинівська культура доби бронзи, метод прискореної мас-спектрометрії

Актуальність теми. Дослідження поселення Сабатинівка I відіграли засадничу роль у становленні археології доби палеометалу Центральної України. Колекція, добута розкопками А.В. Добровольського ${ }^{1}$ з верхнього шару цієї пам'ятки, склала еталонний приклад певного культурного горизонту доби бронзи², а потім, шляхом досить складного історіографічного процесуз, перетворилась на епонімну для однієї з найяскравіших археологічних культур пізнього періоду бронзового віку4. Матеріали сабатинівського шару поселення вдало сполучали невелику добірку металевих виробів (хроноіндикаторів) і виразний керамічний комплекс 5 . Тому до них неодноразово зверталися провідні дослідники для обгрунтування схем хронолого-періодизаційного членування сабатинівської культури та часу пізньої бронзи в ціломуб.

Трипільська колекція з розкопок Сабатинівки I була швидко опублікована Т.С. Пассек7 ${ }^{7}$ перетворивши пам'ятку на один із зразкових об'єктів періоду В1 Трипілля. У подальшому до трипільських матеріалів поселення дослідники звер-

\footnotetext{
1 Добровольський А.В. Перше Сабатинівське поселення // Археологічні пам'ятки УРСР. 1952. Т. 4. С. 78-83.

2 Кривцова-Гракова О.А. Степное Поволжье и Причерноморье в эпоху поздней бронзы Москва: Изд-во АН СССР, 1955. С. 122-132.

3 Гершкович Я.П. Парадоксы в историографии сабатиновской культуры // Stratum Plus. 2002. T. 2. С. 598-607.

4 Шарафутдинова И.Н. К вопросу о сабатиновской культуре // Советская археология. 1968. Т. 3. C. 16-34.

5 Добровольський А.В. Перше Сабатинівське поселення...

6 Черняков И.Т. Северо-Западное Причерноморье во второй половине II тыс. до н.е. Київ: Наукова думка, 1985. С. 55.; Отрощенко В.В. Проблеми періодизації культур середньої та пізньої бронзи півдня Східної Європи (культурно-стратиграфічні зіставлення). Київ: IA HAHУ, 2001. С. 168.

7 Пассек Т.С. Периодизация трипольских поселений (III-II тыс. до н.э.). Москва-Ленинград, 1949.
} 
тались епізодично, в контексті порівнянь і співставлень, вивчення окремих категорій виробів 8 . Лише у 1982 р. було виділено сабатинівську локальну групу пам'яток Трипілля9. Нещодавно, у зв'язку з відкриттям ще 4-5 схожих поселень 10 , це типологічне угрупування набуло особливого значення. Н.Б. Бурдо запропонувала цілісне бачення природи сабатинівської групи 11.

Незважаючи на активне залучення колекцій Сабатинівки I до дискусій і теоретичних побудов ${ }^{12}$, досі шари цієї стратифікованої пам'ятки одержали недостатню кількість радіометричних датувань ${ }^{13}$. Така ситуація створює виразну диспропорцію у системі знань про археологію палеометалу Середнього Побужжя. Відповідно, метою цієї роботи є введення до наукового обігу та попередня інтерпретація невеликої серії датувань, отриманих за верхнім шаром Сабатинівки I, та обгрунтування хронології трипільського шару цієї пам'ятки шляхом порівняння з новими датами, отриманими за типологічно аналогічними поселеннями розташованими неподалік. Таким чином, дослідження просуватиметься у кілька кроків, які відповідають завданням роботи: встановлення абсолютної хронології верхнього шару та порівняння її з відносно-хронологічною позицією його комплексів, ствердження типологічної єдності пам'яток сабатинівської групи Трипілля В1, встановлення датування нижнього шару Сабатинівки I шляхом співставлення добре датованих пам'яток.

Історія вивчення. Поселення Сабатинівка I було відкрито місцевим жителем C.I. Чубом, про що він повідомив у Першомайський окружний краєзнавчий музей ${ }^{14} .3$ серпня 1931 р. його оглянув співробітник Бозької [Бузької] археологічній експедиції К.П. Полікарпович. У 1932 р. поселення розкопувалося під керівництвом П.В.Харламповича. Матеріали цих розкопок опубліковані у відомій роботі Т.С. Пассек і стали частиною її засадничої періодизації Трипілля ${ }^{15}$. Самі ж колекції були втрачені. Експедиція Одеського історико-археологічного музею працювала на Сабатинівці 1 двома загонами: під керівництвом О.Ф. Лагодовської й А.В. Добровольського у 1938-1939 рр. У 1947 р. А.В. Добровольський, вже очолюючи Середньобузьку експедицію Інституту археології АН УРСР, відновив роботи на поселенні. У результаті розкопок 1947 р. А.В.Добровольський значно змінив

\footnotetext{
8 Даниленко В.М., Шмаглій М.М. Про один поворотний момент в історії енеолітичного населення Південної Європи // Археологія. 1972. № 6. С. 3-20; Даниленко В.Н. Энеолит Украины. Этноисторическое исследование. Київ: Наукова думка, 1974.

9 Черныш Е.К. Энеолит Правобережной Украины // Энеолит СССР Москва: Наука, 1982. С. 166-347.

10 Пересунчак С.О. Нові трипільські поселення на Південному Бузі // Земледельцы и скотоводы Древней Европы. Проблемы, новые открытия, гипотезы (дополненное издание). Київ-СанктПетербург: ФОП Корвін-Піотровський А.О., 2012. С. 149-159.

11 Бурдо Н.Б. Место памятников сабатиновского типа в структуре культурного комплекса Кукутень-Триполье // Материалы по археологии Северного Причерноморья. 2015. Т. 13. С. 11-26.

12 Цвек О.В. Структура східнотрипільської культури // Археологія. 1999. № 3. С. 28-40; Palaguta I. Tripolye Culture during the Beginning of the Middle Period(B1): The relative chronology and local grouping of sites Oxford: Hadrian Books, 2007. 182 р.; Бурдо Н.Б. Место памятников сабатиновского типа...

13 Бурдо Н.Б. Сабатинівка I // Енциклопедія трипільської цивілізації. Т. 2. Київ: Укрполіграфмедіа, 2004. C. 457-458.

14 Козубовський Ф.А. Археологічні дослідження на території БОГЕСу 1930-1932 рр. Підсумки археологічних розвідкових робіт в районі майбутнього підтоплення Бозької гідроелектроцентралі. Київ: НКО УСРР, ВУАН, 1933. С. 71-72.

15 Пассек Т.С. Указ. раб.
} 
свої погляди на стратиграфію та характер поселення 16 . Якщо у статті 1941 р. на пам'ятнику був виділений лише один культурний шар, віднесений до трипільської культури, то у 1952 р. видатний український археолог вже чітко розрізняв два мешкання на площі Сабатинівки 1 - трипільської культури й епохи пізньої бронзи. До розкопок 1947 р. умови залягання матеріалу не дозволили стратиграфічно розрізнити ці два шари ${ }^{17}$.

Відбір матеріалів для датування. На сьогодні поселення розташовується на городах кількох садиб с. Сабатинівка на відстані близько 300 м від місця впадіння р. Синиця уздовж лівого берега р. Південний Буг вгору за течією, а також уздовж правого берега р. Синиця на відстані близько 45 м від її устя (Рис. 1).

Зачистка 2 розбита у 200 м на захід від впадіння Синиці до Бугу, на західній частині пам'ятки (Рис. 1: 32), де за А.В. Добровольським присутні тільки матеріали доби пізньої бронзи. Вона має ширину 280 см і прокопана до глибини $250 \mathrm{cm.}$ Відклади дуже дрібночастотні та рихлі. Стратиграфію зачистки 2 описано Ж.М. Матвіїшиною (Рис. 2).

Hd - 0,0-0,1 м дерновий горизонт; Н - 0,1-0,5 м - темно-сірий легкий суглинок; $\mathrm{Hp}$ - 0,5-1,0 м - пилюватий легкий суглинок; $\mathrm{Ph}$ - 1,0-1,2 м -сірий суглинок; Pk 1,2-1,4 м - брудно-сірувато-брунатний піщано-пилюватий легкий суглинок; Hk 1,4-1,6 м - сірий, комкувато-зернистий, піщано-пилюватий легкий суглинок; Hpk - 1,6-1,9 м - сірий з брунатним відтінком, легкий суглинок; Phik - 1,9-2,0 м - cipyвато-брунатний середній суглинок; Pgl - 2,0-2,4 м глейові сірувато-шаруваті тяжкі суглинки.

Зачистка 2 містила матеріали доби бронзи, у тому числі і на досить значній глибині (Рис. 3). Це змушує припускати, що тут виявлено самий низ знищеної схиловими процесами господарської ями. Крім численних крупних кісток тварин тут зібрано і виразну колекцію черепків ліпного посуду, часто дво-, трикольорового у зламі, переважно неорнаментованого. Декор обмежується трьома паралельними валиками на червоногляноному фрагменті стінки з добре-загладженою поверхнею (пн з2/64) та одинарним наліпним валиком (пн з2/50). Наявні і фрагменти відігнутих вінець (пн з2/53, з2/63).

Саме з зачистки 2 було обрано два зразки для радіометричного аналізу. Вони являли собою кістки тварин з зачистки 2 з глибин -122 та -203 см відповідно. Якщо верхній зразок за глибиною відповідає шару доби пізньої бронзи, то нижній, ймовірно, походить з низів заглибленого об'єкту зруйнованого схиловими процесами.

Оскільки достовірних закритих комплексів трипільського часу в ході новітніх польових робіт на поселенні Сабатинівка I не виявлено, то для датування мешкання Трипілля В1 на пам'ятці залучено матеріали з заглиблених об’єктів розташованого неподалік (в 11 км до північного заходу) поселення Березівська ГЕС (Березівка). Зразки відібрано у фондах Одеського археологічного музею НАН України О.П. Секерською з колекції розкопок В.П. Цибескова. Йдеться про уламки кісток тварин з землянок 3 (глибина 120-140 см) та 7 (глибина 140-170 cм).

Методи. Радіометричний аналіз здійснювався у лабораторії LARA Бернського

\footnotetext{
16 Добровольський А.В. Перше Сабатинівське поселення...; Добровольский А.В. Поселение трипольской культуры в с. Сабатиновка на Южном Буге // Материалы по археологии Северного Причерноморья. [1941] 2016. T. XIII. С. 270-282.

17 Добровольський А.В. Перше Сабатинівське поселення... С. 81-83.
} 
університету із застосуванням обладнання MICADAS (міні-системи радіовуглецевого датування) методом прискореної мас-спектрометрії (AMS). Процедура підготовки зразків та їх аналізу відповідає викладеній у роботах ${ }^{18}$. Одержані конвенційні визначення було відкалібровано у програмі OxCal19 із застосуванням калібрувальної кривої IntCal1320.

Результати датування. Нові дати представлені у таблиці 1. Датування з зачистки 2 вказують на вік верхнього культурного шару поселення Сабатинівка I у межах XVI-XV ст. до н.е. По калібруванню вони охоплюють проміжок часу 16111462 та 1526-1438 років каліброваних до н.е. (calBC, за двох стандартних відхилень $(2 \sigma)$, відповідно). Дати частково статистично одночасні й утворюють безперервну і досить щільну послідовність. Дещо старша дата одержана за нижчим зразком. Проте, навряд це може свідчити про наявність кількох хронологічних горизонтів на поселенні, принаймні, на даному етапі вивчення. При комбінуванні датування вказують на проміжок у 1596-1450 років каліброваних до н.е. (calBC, 2б). Критерій ймовірності комбінування свідчить про методичну коректність цієї операції (X2-Test: $\mathrm{df}=1 \mathrm{~T}=1.8$ (5\% 3.8)). У разі підрахунку суми дат на графіку буде два піки вірогідності, проте з плавним переходом між ними. При цьому найбільш вірогідним часом співіснування обох визначень є проміжок 1527-1497 років каліброваних до н.е. calBC (63.4\% ймовірності).

Таблиця 1. Нові датування

\begin{tabular}{|c|c|c|c|c|c|c|}
\hline Походження & Матеріал & $\begin{array}{l}\text { Лаб. } \\
\text { код }\end{array}$ & Дата & $\begin{array}{c}\text { Похиб- } \\
\text { ка }\end{array}$ & $\begin{array}{l}\text { Калібру- } \\
\text { вання, } 1 \sigma\end{array}$ & $\begin{array}{l}\text { Калібру- } \\
\text { вання, } 2 \sigma\end{array}$ \\
\hline $\begin{array}{l}\text { Сабатинівка } 1 \text {, } \\
\text { зачистка } 2, \text { гли- } \\
\text { бина }-122 \text { см }\end{array}$ & $\begin{array}{l}\text { кістка копит- } \\
\text { ної тварини }\end{array}$ & $\begin{array}{c}\text { BE- } \\
10315\end{array}$ & 3220 & 19 & $\begin{array}{l}1506- \\
1453\end{array}$ & $\begin{array}{l}1527- \\
1439\end{array}$ \\
\hline $\begin{array}{l}\text { Сабатинівка } 1, \\
\text { зачистка } 2, \text { гли- } \\
\text { бина - } 203 \text { см }\end{array}$ & $\begin{array}{l}\text { ліва променева } \\
\text { кістка великої } \\
\text { рогатої худоби }\end{array}$ & $\begin{array}{c}\text { BE- } \\
10316\end{array}$ & 3257 & 20 & $\begin{array}{l}1602- \\
1500\end{array}$ & $\begin{array}{l}1611- \\
1464\end{array}$ \\
\hline $\begin{array}{ll}\text { Березівська } & \text { ГЕС, } \\
\text { землянка } 3, & 120- \\
140 \text { см } & \\
\end{array}$ & $\begin{array}{l}\text { кістка (олень } \\
\text { або велика ро- } \\
\text { гата худоба?) }\end{array}$ & $\begin{array}{c}\text { BE- } \\
10317\end{array}$ & 5438 & 21 & $\begin{array}{l}4336- \\
4266\end{array}$ & $\begin{array}{l}4341- \\
4260\end{array}$ \\
\hline $\begin{array}{ll}\text { Березівська } & \text { ГЕС, } \\
\text { землянка 7, } & 140- \\
169 \text { см } & \\
\end{array}$ & $\begin{array}{l}\text { фр-т плеснової } \\
\text { кістки євро- } \\
\text { пейського оле- } \\
\text { ня }\end{array}$ & $\begin{array}{c}\text { BE- } \\
10318\end{array}$ & 5406 & 21 & $\begin{array}{l}4326- \\
4257\end{array}$ & $\begin{array}{l}4331- \\
4240\end{array}$ \\
\hline
\end{tabular}

Дати для заглиблених об’єктів Березівської ГЕС по калібруванню охоплюють хронологічні діапазони 4341-4260 та 4331-4240 pр. кал. до н.е. (calBC, 2б) для землянок 3 і 7, відповідно. Фактично вони є статистично одночасними та коректним

\footnotetext{
${ }^{18}$ Szidat S., Salazar G.A., Vogel E. et al. 14C analysis and sample preparation at the new Bern Laboratory for the Analysis of Radiocarbon with AMS (LARA) // Radiocarbon. 2014. T. 56. P. 561-566; Szidat S., Vogel E., Gubler R. et al. Radiocarbon Dating of Bones at the LARA Laboratory in Bern, Switzerland // Radiocarbon. 2017. T. 59 (3). P. 831-842.

${ }^{19}$ Bronk Ramsey C. Radiocarbon Calibration and Analysis of Stratigraphy: the OxCal Program // Radiocarbon. 1995. T. 37(2). P. 425-430; Bronk Ramsey C., Lee S. Recent and Planned Development of the Program 0xCal // Radiocarbon. 2013. T. 55 (2/3). P. 720-730.

20 Reimer P., Bard E., Bayliss A. et al. IntCal13 and Marine13 radiocarbon age calibration curves 0-50,000 years cal BP // Radiocarbon. 2013. T. 55 (4). P. 1869-1887.
} 
чином (X2-Test: $\mathrm{df}=1 \mathrm{~T}=1.2(5 \% 3.8))$ можуть бути скомбінованими. Проміжок їх співіснування відповідає 4335-4257 рр. кал. до н.е. (calBC, 2б).

Обговорення. 3 точки зору відносної хронології верхній шар Сабатинівського поселення відноситься до розвиненого етапу сабатинівської культури ${ }^{21}$. Останнє явище, зазвичай, датоване у межах XIV-XIII ст. до н.е.22 Враховуючи загальну тенденцію до устародавнення дат, визначених шляхом типологічної серіації по їх перевірці радіовуглецевим методом, можемо говорити про відповідність між новими радіометричними визначеннями й очікуваним датуванням комплексу доби пізньої бронзи Сабатинівки I.

Абсолютна хронологія культурно-історичної спільноти Ноуа-СабатинівкаКослоджень (КІС НСК) визначається на сьогодні достатньою вибіркою датувань ${ }^{23}$. Кількісно значні серії одержано з поселень Одаї-Мічурин, Ротбав, Красналеука24. Вони у цілому охоплюють XVI-XIII ст. до н.е.

Румунські дослідники схильні обмежувати початки КІС НСК пізніми датуваннями культури Віттенберг, які торкаються і XVI ст. до н.е. ${ }^{25}$ Подібна ситуація простежена і для ареалу культури Сабатинівка. Тут їй передують поховання культурного кола Бабине 26 . Радіометричні визначення останнього розподілилися на дві групи: старші (XXIII-XX ст. до н.е.) та молодші (XVII-XV ст. до н.е.). Молодшу групу обгрунтовано ставлять під сумнів шляхом типологічних співставлень з добре датованими комплексами та із загальної логіки історичного процесу27. Подібні міркування можна розширити і на ареал культури Ноуа ${ }^{28}$. Опосередкованим чином на користь цього свідчать нові дати Сабатинівки I. Оскільки це поселення відноситься до розвиненого (другого) етапу сабатинівської культури i, за новими визначеннями датується, найімовірніше, останньою чвертю XVI - початком XV cт. до н.е., варто припускати певний час існування сабатинівської культури, який би передував цьому часовому проміжку. Й отже, початки доби пізньої бронзи, скоріш, відносяться до рубежу XVII/XVI ст. до н.е. ${ }^{29}$, ніж до межі XVI/XV ст. до н.е.

Загальна тенденція до потепління та більшої посушливості в період існування сабатинівської культури археозоологічно виражена у невеликій кількості свиней,

\footnotetext{
21 Черняков И.Т. Указ. раб. С. 55.

22 Gerskovic J. Studien zur spätbronzezeitlichen Sabatinovka-Kultur am unteren Dnepr und an der Westküste des Azov'schen Meeres Rahden: Leidorf, 1999. S. 62; Отрощенко В.В. Указ. раб. С. 163.

${ }^{23}$ Kaiser E., Sava E. Die absolute Datierung der nouazeitlichen Fundstelle Miciurin-Odaia, Nordmoldawien // Der Schwarzmeerraum vom Äneolithikum bis in die Früheisenzeit (5000-500 v. Chr.). Kommunikationsebenen zwischen Kaukasus und Karpaten / Ed. J. Apakidze, B. Govedarica, and B. Hänsel. Rahden: Leidorf, 2009. P. 147-159; Ciugudean H., Quinn C.P. The End of the Wietenberg Culture in the Light of new 14C Dates and its Chronological Relation Towards the Noua Culture // Bronze Age Chronology in The Carpathian Basin. Proceedings of the International Colloquium from Târgu Mureș, 2-4 October 2014 / Ed. R. Nemeth and B. Rezi. Târgu Mureș: Mega, 2015. P. 147-178.

${ }^{24}$ Dascălu L. Bronzul mijlociu şi târziu în Câmpia Moldovei Iasi: Trinitas, 2007; Kaiser E., Sava E. Die absolute Datierung... P. 157; Dietrich L. Datele radiocarbon din aşezarea aparţinând epocii bronzului de la Rotbav (jud. Brașov, România) // Studii și cercetări de istorie veche și arheologie. 2014. T. 65. Vol. 1-2. P. 59-70.

25 Ciugudean H., Quinn C.P. Op. cit. P. 156.

26 Литвиненко Р.А. Культурный круг Бабино: название, таксономия, структура // Краткие сообщения Института археологии АН СССР. 2011. Т. 225. С. 108-122.

27 Мимоход Р.А. Радиоуглеродная хронология блока посткатакомбных культурных образований // Краткие сообщения Института археологии АН СССР. 2011. Т. 225. С. 28-53.

${ }^{28}$ Kaiser E., Sava E. Die absolute Datierung...

${ }^{29}$ Klochko V.I., Kośko A., Szmyt M. A comparative chronology of the Prehistory of the area between the Vistula and Dnieper: 4000-1000 BC // Baltic-Pontic Studies. 2003. T. 12. P. 396-414.
} 
збільшенні поголів'я овець у стаді домашніх тварин і значному зменшенні долі мисливської здобичі сабатинівців. На пам'ятках сабатинівської культури кістки свиней визначені у невеликій кількості ${ }^{30}$. Знайдені на ряді поселень кістки кулана та сайгаку також можна визнати індикаторами аридізації31. У той же час археозоологічні комплекси поселень, розташованих на р. Південний Буг (Бузьке-1, Бузьке-2, Бузьке-4, Виноградний сад, Новогригорівка та Степове) демонструють не тільки велику кількість овець і коней, та незначну роль полювання, але й переважання бика у стаді домашніх тварин. Очевидно, території вдовж течії Південного Бугу давали змогу забезпечити необхідними кормами поголів'я великої рогатої худоби. Мешканці окремих поселень також активно займалися рибальством (Виноградний сад, Дримайлівка). Видовий склад і кількість дикої фауни свідчать на користь переважання степових ландшафтів при існуванні невеликих байрачних і прирічкових лісків. Отже, у цілому, археозоологічні комплекси сабатинівських поселень підтверджують тенденцію до аридизації клімату.

У більш пізніх, за часом, розташованих у степовій зоні сабатинівських поселеннях (Воронівка II) свинарство взагалі не зафіксоване. Хоча велика рогата худоба зберігає панівну позицію, значно збільшується поголів'я коней, а акцент розведення дрібної рогатої худоби зміщується на вівчарство 32 .

Пам'ятки сабатинівської локальної групи Трипілля В1 одержали кілька радіометричних датувань у Київській лабораторії33. Зокрема, було датовано поселення

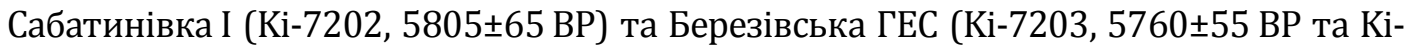
$7204,5710 \pm 60$ ВР). Після калібрування ці визначення охоплюють відрізок 48004400 рр. до н.е. Новітні датування на 200-300 років пізніші та вказують на існування Трипілля B1 Середнього Побужжя у XLIV-XLII ст. до н.е. Вони добре відповідають іншій серії дат, одержаних за матеріалами однотипних поселень Кам'янеЗавалля I та Шамраї. Саме пізня хронологія виглядає більш обгрунтованою. Так, нові дати мають виразно менше стандартне відхилення ніж раніше відомі визначення, перш за все, завдяки використанню методу прискореної мас-спектрометрії. При цьому, пам'ятки сабатинівської групи за імпортами розписної кераміки синхронізуються з фазами Кукутені А3-А434. Розвиток останніх, з точки зору аналогічних радіометричних серій, обмежується другою половиною V тис. до н.е. 35

Нові дати існування поселення Березівська ГЕС у цілому узгоджуються із результатами дослідження археозоологічного комплексуз3.

\footnotetext{
30 Секерская Е.П. Скотоводческо-охотничья деятельность населения эпохи поздней бронзы на территории юга Украины // Stratum Plus. 1999. № 2. С. 257.

31 Журавлев О.П. Домашние и дикие животные из поселений сабатиновской культуры на территории Украины // Історична наука: проблеми розвитку: Археологія. Луганск, 2002. С. 78-81 .

32 Секерская Е.П. Скотоводство и охота в хозяйстве позднебронзового поселения Вороновка II // B.Н. Станко (ред.). Вороновка II. Поселение позднего бронзового века в Северо-Западном Причерноморье. Киев: Наукова думка, 1991. С. 67.

33 Бурдо Н.Б. Новые данные для абсолютной датировки неолита и раннего энеолита на территории Украины // Stratum plus. 2001-2002. № 2. С. 431-446.

34 Бурдо Н.Б. Место памятников сабатиновского типа...

35 Mischka C., Preoteasa C., Schafferer G. Gradiometerprospektionen auf Fundplatzen der CucuteniKultur im Kreis Neamt (Rumanien) // Eurasia Antiqua. 2016 (2019). T. 22. P. 115-131; Hofmann R., Müller J., Shatilo L. et al. Governing Tripolye: Integrative architecture in Tripolye settlements // PLoS ONE. 2019. T. 14 (9). e0222243.

36 Сєкерська О.П. Археозоологічний комплекс і модель тваринництва та полювання мешканців трипільського поселення «Березовська ГЕС» // Емінак: наук. журнал. 2020. № 1 (29). С. 292-303.
} 
Загальна кількість диких тварин складає понад половину усіх особин ссавців. Основну частину мисливської здобичі складали великі копитні тварини, серед яких переважають європейський олень, кабан і козуля. Рідше здобували тура та коня. Біотопами переважної більшості цих видів $\epsilon$ змішані лісостепові ландшафти. Наявність у матеріалах поодиноких кісток кулана та сайгаку - типових мешканців відкрити степових рівнинних територій, може засвідчувати тенденцію до поступового поширення степової рослинності, яка могла мати місце наприкінці фази оптимуму вологості та розвитку широколистяної рослинності. В окремі, більш посушливі сезони, ці види могли просуватися у північно-західному напрямку та досягати лісостепової смуги. Окремі види свідчать на користь існування навколо Березівської ГЕС також великих масивів широколистяних лісів (індикаторами останніх $\epsilon$ такі види як ведмідь, лісова куниця, рись, лось, бобер). Якщо бобер може мешкати у прирічкових лісах степової смуги, то лісова куниця - типовий мешканець лісів. Лось віддає перевагу заростаючим вирубкам і розрідженим лісам, а ведмідь і рись - більш густим лісовим масивам.

Велика кількість свиней у стаді домашніх тварин $(26,7 \%$ особин) і кіз (останні могли становити близько половини поголів'я дрібної рогатої худоби, тобто, 7-8\% особин) також свідчить на користь переважання лісостепових ландшафтів.

Отже, поселення існувало у лісостеповому ландшафті у відносно вологих кліматичних умовах, але вже намічалася тенденція до поширення степової рослинності та збільшення температур.

Висновки. Таким чином, підтверджується висновок А.В. Добровольського про те, що «між шарами А та Б Сабатинівського поселення проміжок у, щонайменше, 1500 років»37. Проміжок виявився насправді тривалішим - у 2700 років. Нижній шар Трипілля B1 (опосередковано, за датуванням аналогічних пам'яток) датується XLIV-XLII ст. до н.е. Встановлення цієї дати має значні імплікації, особливо для синхронізації культурних явищ «степового енеоліту». Верхній шар сабатинівської культури датується XVI-XV ст. до н.е., найімовірніше останньою третиною XVI - початком XV ст. до н.е. Визначення хронології цього комплексу відкриває додаткові можливості вивчення початків пізнього періоду доби бронзи у Середньому Побужжі.

Подяки. Автори щиро вдячні д. геогр. н. Ж.М. Матвіїшиній за опис розрізу зачистки 2 на Сабатинівці I, пану Г.Г. Тавровському та Л. Семікіній (власникам ділянок, на яких проводилися роботи), а також студентам ОНУ ім. І.І. Мечникова, у межах практик яких здійснювались польові роботи на пам'ятці. Радіовуглецеве датування здійснено у межах програми SNF SCOPES, IZ73Z0_152732.

\section{REFERENCES}

Bronk Ramsey, B.C. (1995). Radiocarbon Calibration and Analysis of Stratigraphy: The OxCal Program. Radiocarbon, 37 (2), 425-430.

Bronk Ramsey, B.C. \& Lee, S. (2013). Recent and Planned Development of the Program OxCal. Radiocarbon, 55 (2/3), 720-730.

Burdo, N.B. (2001-2002). Novye dannye dlia absoliutnoi datirovki neolita i rannego eneolita na territorii Ukrainy [New data for absolute dating of the Neolithic and Early Eneolithic on the Ukraine territory]. Stratum plus, 2, 431-446 [in Russian].

Burdo, N.B. (2004). Sabatynivka I [Sabatynivka I]. In Novokhatko, L.M. (Ed.), Entsyklopediia trypilskoi tsyvilizatsii, (Vol. 2, pp. 457-458). Kyiv: Ukrpoligrafia [in Ukrainian].

37 Добровольський А.В. Перше Сабатинівське поселення... С. 79. 
Burdo, N.B. (2015). Mesto pamiatnikov sabatinovskogo tipa v strukture kulturnogo kompleksa Kukuten-Tripole [The place of the Sabatin type monuments in the structure of the cultural complex Kukuten-Tripolie]. Materialy po arkheologii Severnogo Prichernomoria, 13, 11-26 [in Russian].

Cherniakov, I.T. (1985). Severo-Zapadnoe Prichernomorie vo vtoroi polovine II tys. do n.e. [Northwestern Black Sea Region in the Second Half of the $2^{\text {nd }}$ millennium BC]. Kyiv: Naukova dumka [in Russian].

Chernysh, E.K. (1982). Eneolit Pravoberezhnoi Ukrainy. In Masson, V.M. \& Merpert, N.Y. (Eds.). Eneolit SSSR (pp. 166-347). Moskva: Nauka [in Russian].

Ciugudean, H., \& Quinn, C.P. (2015). The End of the Wittenberg Culture in the Light of new 14C Dates and its Chronological Relation Towards the Noua Culture. In Nemeth, R. \& Rezi, B. (Eds.). Bronze Age Chronology in The Carpathian Basin. Proceedings of the International Colloquium from Târgu Mureș, 2-4 October 2014 (pp. 147-178). Târgu Mureş: Mega.

Danylenko, V.M. (1974). Eneolit Ukrainy. Etnoistoricheskoe issledovanie. [Eneolithic of Ukraine. Ethnohistorical research]. Kyiv: Naukova dumka [in Russian].

Danylenko, V.M., \& Shmahlii, M.M. (1972). Pro odyn povorotnyi moment v istorii eneolitychnoho naselennia Pivdennoi Yevropy [On a turning point in the history Eneolithic population of Southern Europe]. Arkheolohiia, 6, 3-20 [in Ukrainian].

Dascălu, L. (2007). Bronzul mijlociu şi târziu în Câmpia Moldovei. Iasi: Trinitas [in Romanian].

Dietrich, L. (2014). Datele radiocarbon din aşezarea aparţinând epocii bronzului de la Rotbav (jud. Braşov, România). Studii și cercetări de istorie veche și arheologie, 65 (1-2), 59-70 [in Romanian].

Dobrovolskyi, A.V. ([1941] 2016). Poselenie tripolskoi kultury v s. Sabatinovka na Yuzhnom Buge [Settlement of Tripoli culture in the village of Sabatinovka on the South Bug]. Materialy po arkheologii Severnogo Prichernomoria, XIII, 270-282 [in Ukrainian].

Dobrovolskyi, A.V. (1952). Pershe Sabatynivske poselennia [The first settlement Sabatynivka]. Arkheolohichni pam'iatky URSR, 4, 78-83 [in Ukrainian].

Gerskovic, J. (1999). Studien zur spätbronzezeitlichen Sabatinovka-Kultur am unteren Dnepr und an der Westküste des Azov'schen Meeres. Rahden: Leidorf.

Hershkovich, Y.P. (2002). Paradoksy v istoriografii sabatinivskoi kultury [Paradoxes in the historiography of the Sabatinovka culture]. Stratum Plus, 2, 598-607 [in Russian].

Hofmann, R., Müller, J., Shatilo, L., Videiko, M., Ohlrau, R., Rud, V. \& Kirleis, W. (2019). Governing Tripolye: Integrative architecture in Tripolye settlements. PLOS ONE, 14(9), e0222243.

Kaiser, E., \& Sava, E. (2009). Die absolute Datierung der nouazeitlichen Fundstelle Miciurin-Odaia, Nordmoldawien. In Apakidze J., Govedarica B. \& Hänsel B. (Eds.). Der Schwarzmeerraum vom Äneolithikum bis in die Früheisenzeit (5000-500 v. Chr.). Kommunikationsebenen zwischen Kaukasus und Karpaten (pp. 147-159). Rahden: Leidorf.

Klochko, V.I., Kośko, A., \& Szmyt, M. (2003). A comparative chronology of the Prehistory of the area between the Vistula and Dnieper: 4000-1000 BC. Baltic-Pontic Studies, 12, 396-414.

Kozubovskyi, F.A. (1933). Arkheolohichni doslidzhennia na terytorii BOHESu 1930-1932 rr. Pidsumky arkheolohichnykh rozvidkovykh robit $v$ raioni maibutnoho pidtoplennia Bozkoi hidroelektrotsentrali [Archaeological research on the territory of BOHES 1930-1932. Results of archeological exploration works in the area of future flooding of the Bug hydroelectric power plant]. Kyiv: VUAN [in Russian].

Krivtsova-Grakova, O.A. (1955). Stepnoe Povolzhe i Prichernomore v epokhu pozdnei bronzy [Steppe Volga region and the Black Sea coast in the Late Bronze Age]. Moskva: Izd-vo AN SSSR [in Russian].

Lytvynenko, R.A. (2011). Kulturnyi krug Babino: nazvanie taksonomiia struktura [Babino cultural circle: Name, taxonomy, and structure]. Kratkie soobshcheniia Instituta arkheologii AN SSSR, 225, 108122 [in Russian].

Mimokhod, R.A. (2011). Radiouglerodnaia khronologiia bloka postkatakombnykh kulturnykh obrazovanii [Radiocarbon chronology of post-Catacomb cultural units]. Kratkie soobshcheniia Instituta arkheologii AN SSSR, 225, 28-53 [in Russian].

Mischka, C., Preoteasa, C., \& Schafferer, G. (2016 (2019)). Gradiometerprospektionen auf Fundplatzen der Cucuteni-Kultur im Kreis Neamt (Rumanien). Eurasia Antiqua, 22, 115-131.

Otroshchenko, V.V. (2001). Problemy periodyzatsii kultur serednoi ta piznoi bronzy pivdnia Skhidnoi Yevropy (kulturno-stratyhrafichni zistavlennia) [Problems of Periodization of Cultures of Middle and Late Bronze in Southern Eastern Europe (cultural-stratigraphic comparisons)] Kyiv: IA NANU [in Russian]

Palaguta, I. (2007). Tripolye Culture during the Beginning of the Middle Period (B1): The relative chronology and local grouping of sites. Oxford: Hadrian Books.

Passek, T.S. (1949). Periodizatsiia tripolskikh poselenii III-II tys. do n. e. [Periodization of Tripolie settlements III-Ith millenniums BC]. Moskva-Leningrad: MIA [in Russian]. 
Peresunchak, S.o. (2012). Novi trypilski poselennia na Pivdennomu Buzi [New Tripolie settlements on South Bug]. In Otroshchenko, V.V. (Ed.). Zemledeltsy i skotovody Drevnei Evropy: Problemy, novye otkrytiia, gipotezy (pp. 149-159). Kyiv-Saint-Petersburg.: FOP Korvin-Piotrovskyi A.O. [in Ukrainian].

Reimer, P., Bard, E., Bayliss, A., Beck, J., Blackwell, P., Bronk Ramsey, C. \& van der Plicht, J. (2013). IntCal13 and Marine13 radiocarbon age calibration curves 0-50,000 years cal BP. Radiocarbon, 55 (4), 1869-1887.

Sekerskaya, E.P. (1999). Skotovodchesko-okhotnichia deyatelnost naseleniya epokhi pozdney bronzy na territorii yuga Ukrainy [Cattle breeding and hunting activity of the Late Bronze Age population in the South Ukrainian region]. Stratum plus, 2, 256-264 [in Russian].

Siekerska, 0.P. (2020). Arkheozoolohichnyi kompleks i model tvarynnytstva ta poliuvannia meshkantsiv trypilskoho poselennia «Berezovska HES». [Archeozoological complex and model of animal husbandry of the inhabitants from the Trypillian settlement «Berezovska GES»]. Eminak, 1, 292-303 [in Ukrainian].

Sekerskaya, E.P. (1991). Skotovodstvo i okhota v khozyaystve pozdnebronzovogo poseleniya Voronovka II [Cattle breeding and hunting in the economy of the Late Bronze Age settlement Voronovka 2]. In: Stanko V.N. (Ed). Voronovka II. Poseleniye pozdnego bronzovogo veka v SeveroZapadnom Prichernomorye. Kiev: Naukova dumka, 67-69 [in Russian].

Sharafutdinova, I.N. (1968). K voprosu o sabatinovskoi kulture [On the question of Sabatinovka culture]. Sovetskaia arkheologiia, 3, 16-34 [in Russian].

Szidat, S., Salazar, G.A., Vogel, E., Battaglia, M., Wacker, L., Synal, H.-A., \& Türler, A. (2014). 14C analysis and sample preparation at the new Bern Laboratory for the Analysis of Radiocarbon with AMS (LARA). Radiocarbon, 56, 561-566. DOI: 10.2458/56.17457

Szidat, S., Vogel, E., Gubler, R., \& Lösch, S. (2017). Radiocarbon dating of bones at the LARA Laboratory in Bern, Switzerland. Radiocarbon, 59, 831-842. DOI: 10.1017/RDC.2016.90.

Tsvek, O.V. (1999). Struktura skhidnotrypilskoi kultury [Structure of Easter Tripolie culture]. Arkheolohiia, 3, 28-40 [in Russian].

Zhuravlev, O.P. (2002). Domashniye i dikiye zhivotnyye iz poseleniy sabatinovskoy kultury na territorii Ukrainy [Domestic and wild animals from the settlements of Sabatinovka culture on the territory of Ukraine]. In Materialy mizhnarodnoi naukovoi konferentsii (17-18 travnia 2002 r.). Luhansk, P. 75-82 [in Russian].

\section{Dmytro Kiosak}

(Odesa I.I. Mechnikov National University, Odesa, Ukraine)

e-mail: dkiosak@ukr.net

ORCID: https://orcid.org/0000-0002-3349-4989

\section{Olena Siekerska}

(South Ukrainian National Pedagogical University named after K.D. Ushynsky, Odesa, Ukraine) e-mail: e.sekerskaja@gmail.com

ORCID: https://orcid.org/0000-0003-4540-3308

\section{New Data on Chronology of Stratified Settlement Sabatynivka-1}

The chronology of the Paleometal Age of the Southern Buh region remains determined only in the most general features. Modern conceptions are based mainly on a few cases of direct stratigraphy and typological seriation. The lack of radiometric determinations for stratified sites is particularly noticeable.

This paper presents four new radiocarbon datings based on dating animal bones. The datings were aimed at determining the absolute chronology of two layers of Sabatynivka settlement: the lower (Trypillia B1) and the upper (Late Bronze Age).

For dating the upper layer, the samples were taken from a closed context, the Bronze Age pit destroyed by slope processes.

Taking into account the lack of materials suitable for dating from authentic contexts of Trypillia B1 at Sabatynivka-1, the chronology of the lower layer was determined by dating 
bones of deepened objects at the site of the settlement located nearby, Berezivka HPP (hydroelectric power plant), a similar complex of material culture.

The analysis was performed by accelerator mass spectrometry, which provided much more accurate determinations than those available so far. Obtained data indicate that the formation of the lower layer took place within the $44^{\text {th }}-42^{\text {nd }}$ centuries BCE, and the upper layer within $16^{\text {th }}-15^{\text {th }}$ centuries BCE.

The new datings meet modern ideas about the relative chronological position of both layers. Thus, the settlement of Sabatynivka-1 belongs to the developed (second) stage of Sabatynivka culture and, according to gained results, dates, most likely, to the last quarter of the $16^{\text {th }}$ - the beginning of the $15^{\text {th }}$ century BCE. Therefore, we can assume a certain time of existence of Sabatynivka culture in its first period, preceding the mentioned time period, and this moves the dating of this community appearing back to the end of the $17^{\text {th }}$ - beginning of the $16^{\text {th }}$ century BCE. On imports of painted pottery, the sites of Sabatynivka group of Trypillia B1 are synchronized with the Cucuteni A3-A4 phases. The development of the latter in terms of similar radiometric series from other regions of Trypillia-Cucuteni cultural complex spreading is limited to the second half of $5^{\text {th }}$ millennium BCE.

Thus, the chronological benchmarks for the development of microregional chronology of the Paleometal Age of the Southern Buh region are established.

Keywords: radiocarbon analysis, Trypillia B1, Sabatynivka culture of the Bronze Age, method of accelerator mass spectrometry 


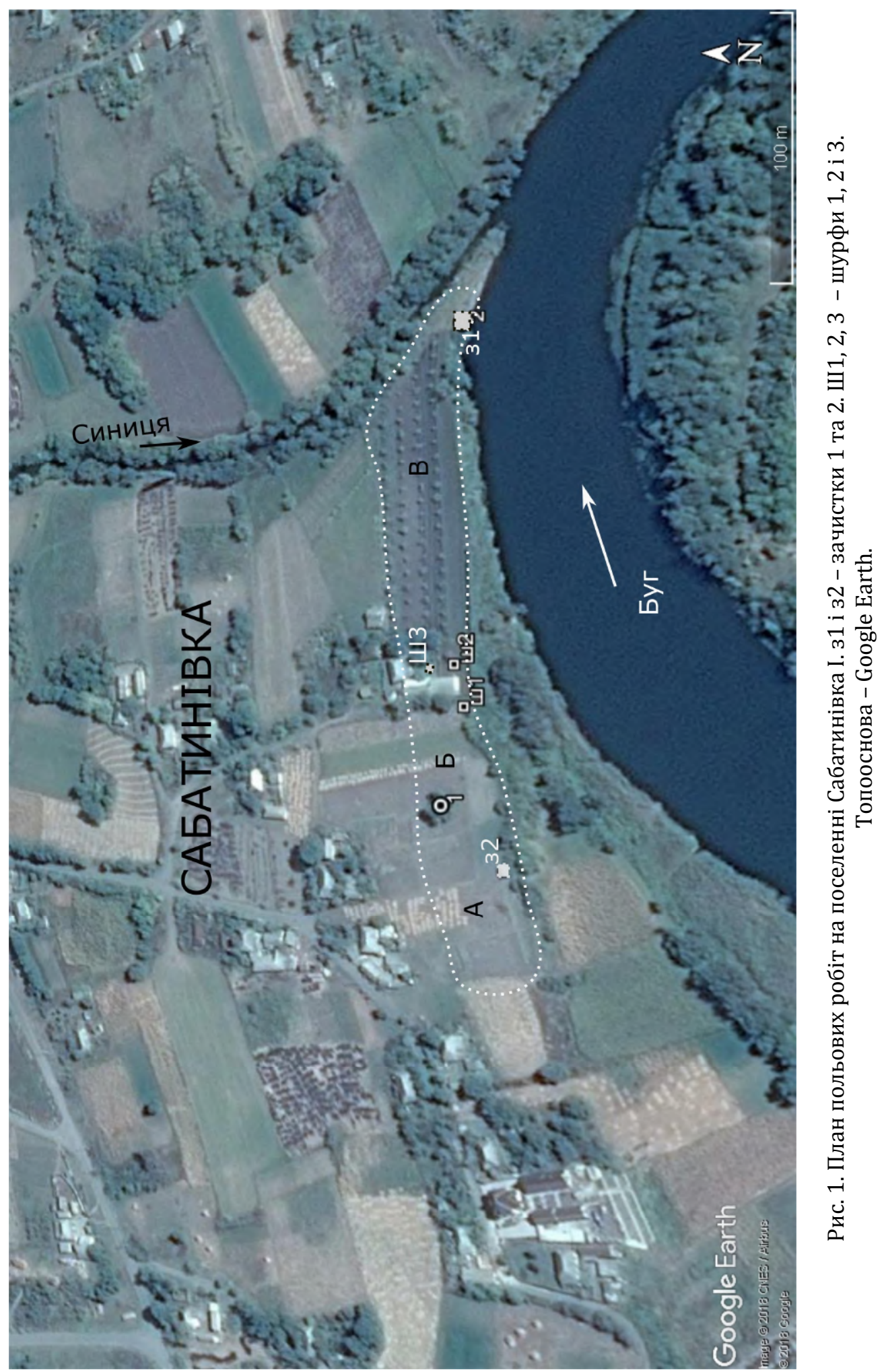




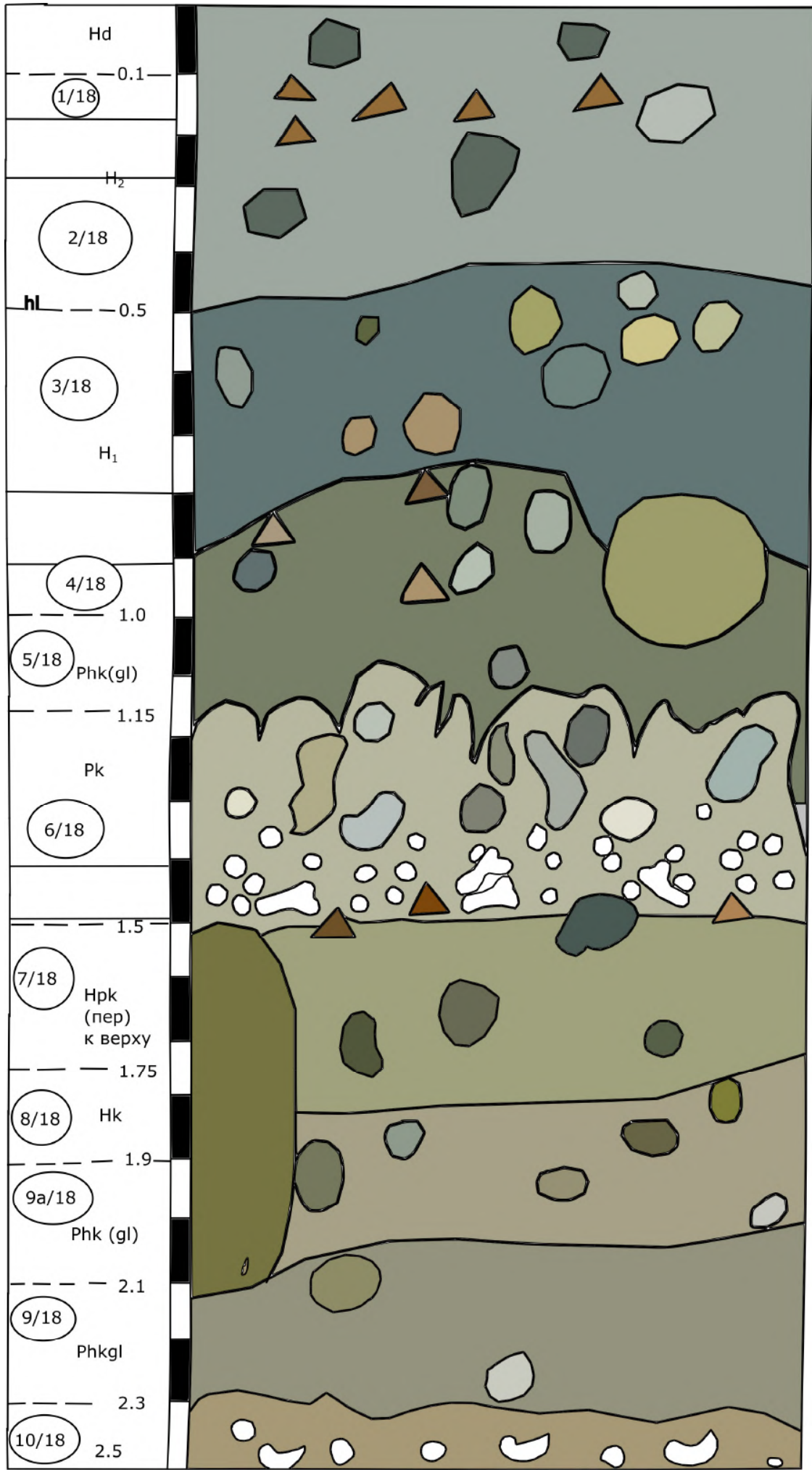

Рис. 2. Стратиграфія зачистки 2 за Ж.М. Матвіїшиною. Позначення - див. текст. 


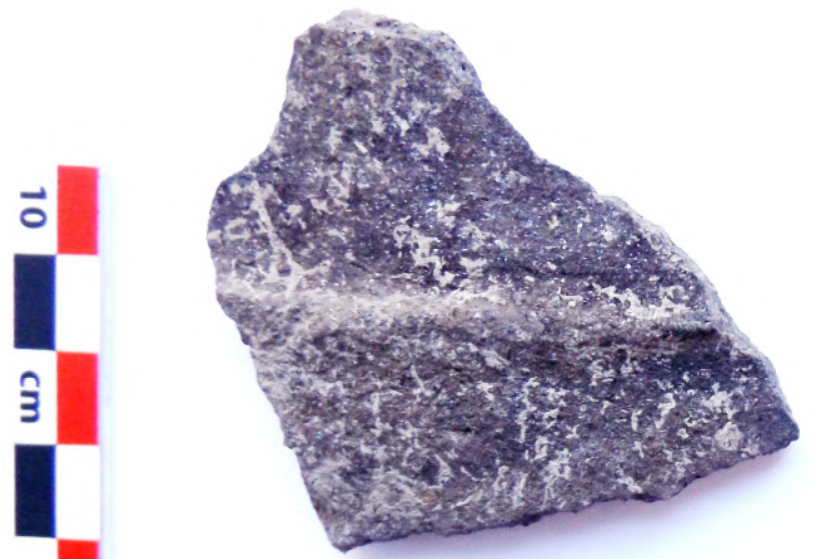

п.н. 50

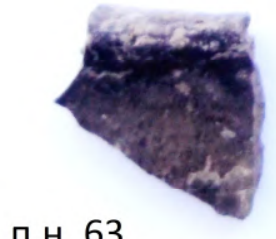

п.н. 63
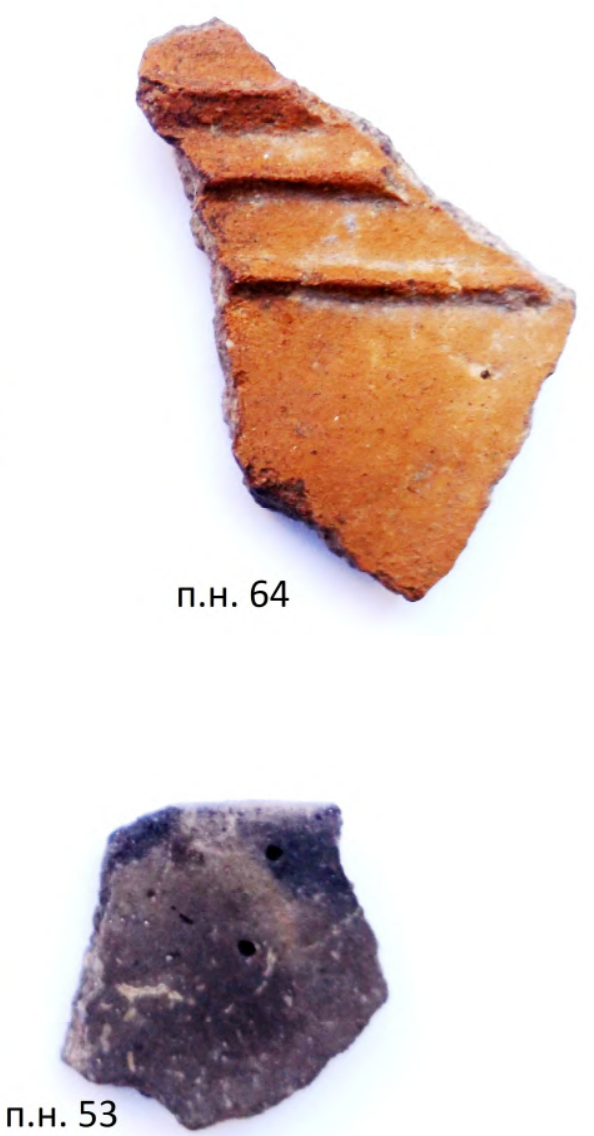

Рис. 3. Матеріали із зачистки 2. 


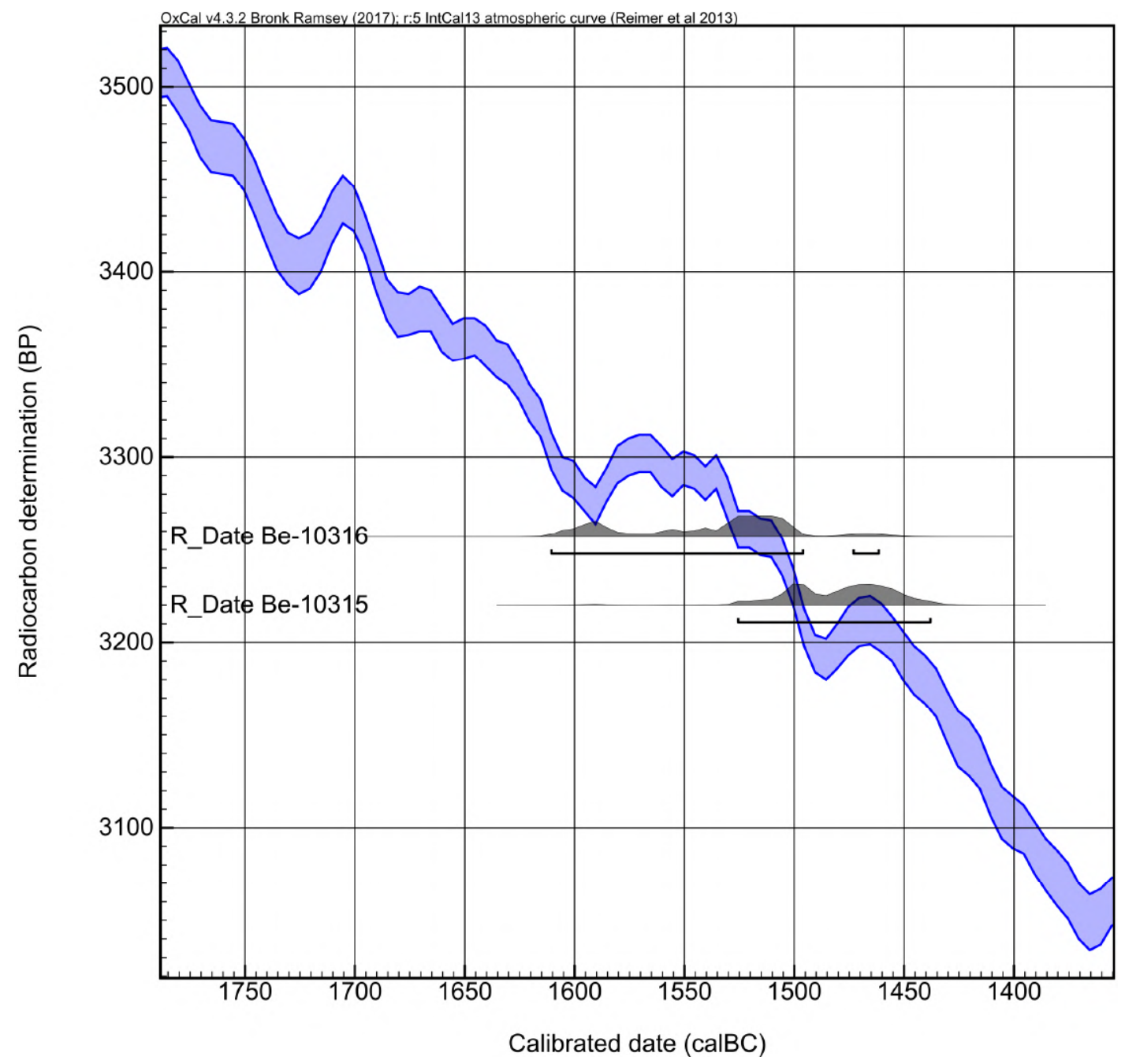

Рис. 4. Калібрування радіовуглецевих дат для поселення Сабатинівка 1. 


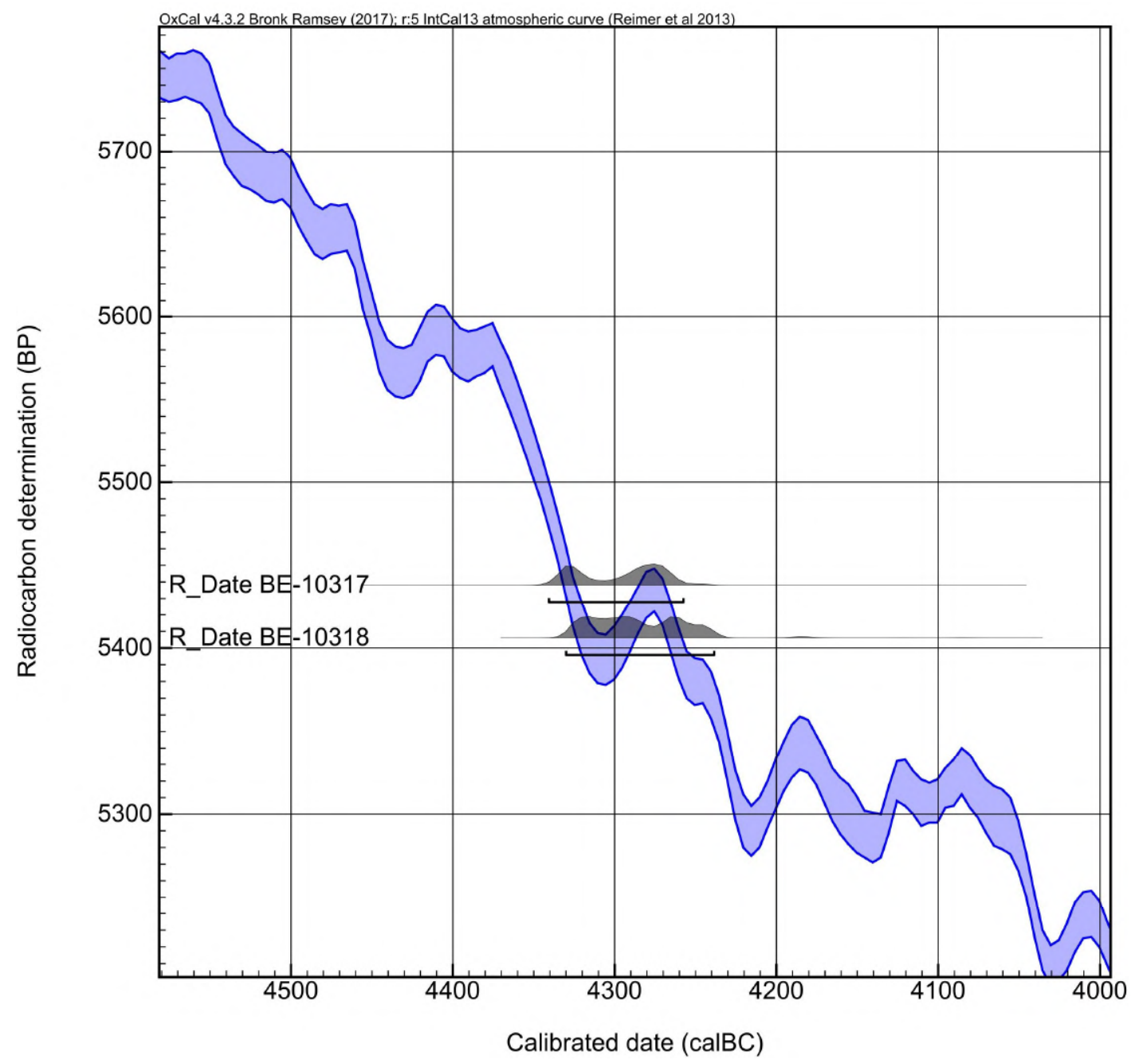

Рис. 5. Калібрування радіовуглецевих дат для поселення Березівська ГЕС. 